\title{
Postdural puncture headache
}

Korean Journal of Anesthesiology

\author{
Kyung-Hwa Kwak \\ Department of Anesthesiology and Pain Medicine, School of Medicine, Kyungpook National University, Daegu, \\ Korea
}

Postdural puncture headache (PDPH) is a common complication after inadvertent dural puncture. Risks factors include female sex, young age, pregnancy, vaginal delivery, low body mass index, and being a non-smoker. Needle size, design, and the technique used also affect the risk. Because PDPH can be incapacitating, prompt diagnosis and treatment are mandatory. A diagnostic hallmark of PDPH is a postural headache that worsens with sitting or standing, and improves with lying down. Conservative therapies such as bed rest, hydration, and caffeine are commonly used as prophylaxis and treatment for this condition; however, no substantial evidence supports routine bed rest and aggressive hydration. An epidural blood patch is the most effective treatment option for patients with unsuccessful conservative management. Various other prophylactic and treatment interventions have been suggested. However, due to a lack of conclusive evidence supporting their use, the potential benefits of such interventions should be weighed carefully against the risks. This article reviews the current literature on the diagnosis, risk factors, pathophysiology, prevention, and treatment of PDPH.

Key Words: Epidural blood patch, Postdural puncture headache.

\section{Introduction}

Postdural puncture headache (PDPH) is a major complication of neuraxial anesthesia that can occur following spinal anesthesia and with inadvertent dural puncture during epidural anesthesia. Obstetric patients are considered at increased risk for this condition because of their sex, young age, and the widespread use of neuraxial blocks. Inadvertent dural puncture during epidural anesthesia is a more common cause of $\mathrm{PDPH}$

Corresponding author: Kyung-Hwa Kwak, M.D., Ph.D.

Department of Anesthesiology and Pain Medicine, School of Medicine, Kyungpook National University, 130, Dongdeok-ro, Jung-gu, Daegu 41944, Korea

Tel: 82-53-200-2641, Fax: 82-53-426-2760

Email:kwakkh@knu.ac.kr

ORCID: http://orcid.org/0000-0003-0819-1764

Received: November 18, 2016.

Revised: November 24, 2016.

Accepted: December 19, 2016.

Korean J Anesthesiol 2017 April 70(2): 136-143

https://doi.org/10.4097/kjae.2017.70.2.136 than spinal anesthesia because of the use of small, pencil-point needles for spinal anesthesia in this population. During epidural placement, inadvertent puncture of the dura mater occurs at a rate of $1.5 \%$ (95\% CI 1.5-1.5\%), and more than half (52.1\%; 95\% CI: 51.4-52.8\%) of these patients develop PDPH [1]. A more recent study showed that the incidence of $\mathrm{PDPH}$ after dural puncture with an epidural needle could be as high as 76-85\% [2].

Although PDPH usually resolves spontaneously, it has the potential to cause significant morbidity in obstetric patients. It can also interfere with the mother's ability to take care of herself or her baby, and may extend the length of hospital stay or evolve into chronic headache. In a retrospective case-control study, Webb et al. [3] reported that chronic headache occurred in $28 \%$ of obstetric women after inadvertent dural puncture with a 17-gauge Tuohy needle. Preventing PDPH should be the primary goal of clinicians dealing with this population. In fact, proper attention to procedure-related factors can significantly reduce its incidence. Occasionally, inadvertent dural puncture and PDPH are unavoidable complications. Therefore, anesthesiologists need to be familiar with treatment modalities and prevention. This review summarizes current concepts regarding the diagnosis, pathophysiology, risk factors, prevention, and treatment of PDPH.

(ㄷ) This is an open-access article distributed under the terms of the Creative Commons Attribution Non-Commercial License (http://creativecommons.org/ licenses/by-nc/4.0/), which permits unrestricted non-commercial use, distribution, and reproduction in any medium, provided the original work is properly cited. 


\section{Clinical Symptoms and Diagnosis}

PDPH presents as a dull throbbing pain with a frontal-occipital distribution. Typically, the headache is aggravated by sitting or standing, and is reduced by lying down [4]. The diagnosis should be questioned in the absence of a postural component of the headache. At least partial relief should occur when the patient assumes the supine position. According to the International Classification of Headache Disorders criteria for the diagnosis of PDPH, headache develops within 5 days after dural puncture and disappears spontaneously within 1 week, or up to $48 \mathrm{~h}$ after an epidural blood patch. The headache may be accompanied by neck stiffness, tinnitus, hypoacusia, photophobia, and nausea [5]. However, recent studies indicate that PDPH occurs within 3 days after dural puncture [6-8], and up to $29 \%$ of patients have headache as the only symptom [6]. Rarely, the headache may last for months or even years [9]. Postpartum headaches are very common, developing in $39 \%$ of women, and tension and migraine headaches are more common in pregnant than nonpregnant women [10]. Therefore, when diagnosing PDPH in obstetric patients, it is important to exclude other causes of headache, such as functional headaches. Less frequent complications of accidental dural puncture include reversible encephalopathy [11-13], pneumocephalus [14], and subdural hematoma [15,16]. Therefore, when neurological signs or changes in headache characteristics such as non-postural headache occur, serious etiologies should be excluded such as subdural hematoma, cerebral thrombosis, and reversible encephalopathy [17].

\section{Pathophysiology}

In 1899, August Bier pioneered work on spinal anesthesia and first described PDPH, suggesting that it might be caused by cerebral spinal fluid (CSF) loss. Although the precise mechanism of this condition remains unknown, the postulated cause of the headache is reduced CSF pressure due to loss of CSF in the epidural space through the dural puncture site [18]. Decreased CSF pressure creates a loss of the cushioning effect normally provided by intracranial fluid. The resulting traction placed on intracranial pain-sensitive structures elicits pain [18]. A second possible cause is distension of the cerebral blood vessels. With a sudden drop in CSF pressure, vasodilation of the intracranial vessels occurs to maintain a constant intracranial volume, resulting in a pathophysiology similar to vascular headache [19]. The beneficial effects of vasoconstrictor drugs such as caffeine and theophylline in PDPH support this mechanism.

\section{Risk Factors}

\section{Patient factors}

The well-known risk factors of PDPH include young age, female sex, and pregnancy. Young adults are at higher risk of developing this condition than older individuals (14\% vs. 7\%) [20] because with increasing age, the dura may be less elastic and less likely to gape. Women, particularly during pregnancy, are considered at increased risk for PDPH [6,21]. Its high incidence may be attributed to increased estrogen levels, which influence the tone of the cerebral vessels, thereby increasing the vascular distension in response to CSF hypotension [6,21,22]. Another risk factor for PDPH is vaginal delivery. Pushing efforts during the second stage can increase the size of the dural hole and CSF loss. However, two retrospective studies examining whether second-stage pushing increased the incidence and severity of $\mathrm{PDPH}$ or the need for an epidural blood patch reported conflicting results [23,24].

Some evidence suggests that morbidly obese patients have a decreased incidence of PDPH [25-27]. The increase in epidural pressure observed in obese compared to thin patients may lessen the pressure gradient from the intrathecal space to the epidural space, decreasing the loss of CSF. However, again, retrospective studies have revealed conflicting results [28]. In a retrospective review of the records of 125 parturient women with accidental dural puncture or PDPH, Miu et al. [28] found no evidence that women with a high body mass index (BMI) are less likely to develop PDPH or require an epidural blood patch. In contrast, in a retrospective review of 518 parturient women who experienced accidental dural puncture, Peralta et al. [29] reported that the incidence of PDPH in parturients with a BMI $\geq 31.5 \mathrm{~kg} / \mathrm{m}^{2}(39 \%)$ was lower than that in those with a BMI $<31.5 \mathrm{~kg} / \mathrm{m}^{2}(56 \%$; difference $=-17 \%, 95 \% \mathrm{CI}-7 \%$ to $-26 \%, \mathrm{P}=0.0004)$. However, the BMI did not affect the severity of PDPH or the need for an epidural blood patch.

In a retrospective chart review of 153 patients who received an epidural catheter through a 17-gauge Tuohy needle for continuous CSF sampling, Dodge et al. [30] investigated the effects of cigarette smoking on the risk of PDPH and found that smokers had a lower incidence of PDPH compared to non-smokers (13.7\% vs. $34.1 \%, \mathrm{P}=0.009$ ). Although the mechanism is uncertain, the authors proposed that smoking promotes blood clotting and may facilitate closure of the dural hole by a clot.

\section{Needle design, size, and direction}

The type and size of needle are also important factors in $\mathrm{PDPH}$, given that research clearly demonstrates that larger dural tears result in a higher incidence of this condition. Cutting nee- 
dles (Quincke needles) are associated with a higher incidence of PDPH compared to blunt or pencil-point needles (Sprotte and Whitacre needles). Schmittner et al. [31] and Gisore et al. [32] confirmed the significantly lower incidence of PDPH with pencil-point needles compared to Quincke cutting needles in similar studies $(1.7 \%$ vs. $6.6 \%, \mathrm{P}=0.02$ and $4.5 \%$ vs. $24.2 \%, \mathrm{P}=$ 0.042). A modification of the Quincke (Atraucan) needle is also available, with a cutting point and a double bevel to cut a small dural hole and then dilate it. Several studies have confirmed that the bigger the needle, the greater the incidence of PDPH [19,33-35]. With Quincke needles, the incidence and severity of $\mathrm{PDPH}$ is directly related to the size of the needle. A similar effect may occur with pencil-point needles.

Another needle-related factor that results in a reduced incidence of PDPH is the orientation of the needle bevel parallel to the long axis of the spine, resulting in decreased disruption of dural fibers [36]. This longitudinal bevel orientation separates the dural fibers rather than cuts them, which facilitates closure of the dural hole on withdrawing the needle. A longitudinal orientation of the needle bevel has been confirmed to reduce the risk of PDPH compared to perpendicular insertion [37,38]. Regarding the direction of the bevel of a Tuohy needle, Norris et al. [37] reported a decreased incidence of PDPH when the bevel entered the epidural space along the long axis of the spine and then was rotated 90 degrees before inserting the catheter compared to keeping a perpendicular approach.

\section{Prophylactic Interventions}

\section{Conservative}

When unintentional dural puncture occurs, several conservative therapies are commonly used, such as hydration and bed rest. These therapies aim to decrease CSF loss through the dural hole and restore CSF with additional fluid intake [39]. These methods are simple and do not have any serious adverse effects, but no conclusive evidence supports their use for the prevention of PDPH [40,41]. Particularly during the puerperium, early ambulation is recommended due to the risk of deep vein thrombosis and pulmonary embolism because of hypercoagulability. The authors of a 2016 Cochrane review [40] found no evidence suggesting that routine bed rest after a dural puncture is beneficial for preventing PDPH (risk ratio [RR]: 1.16, 95\% CI: 1.02-1.32). Furthermore, bed rest likely increased PDPH (RR: 1.24, 95\% CI: 1.04-1.48) compared to early ambulation. There was also no evidence to support a benefit of prophylactic fluid supplementation (RR: 1, 95\% CI: 0.59-1.69). Several prophylactic drugs have been studied, but their clinical effectiveness has not been established. For example, epidural morphine [42] and intravenous cosyntropin [43] have shown promising effects in the prevention of PDPH after dural puncture. However, neither is recommended routinely due to side effects and limited evidence.

\section{Invasive}

\section{Prophylactic epidural blood patch}

A prophylactic epidural blood patch can be performed through the epidural catheter, which is re-sited after inadvertent dural puncture, just before the epidural catheter is removed. Autologous blood injected into the epidural space is thought to seal the dural defect. Therefore, the use of a prophylactic epidural blood patch might prevent PDPH and the need for further treatments in that regard. However, recent systemic reviews with a meta-analysis of four randomized controlled studies have not conclusively supported the use of a prophylactic epidural blood patch for preventing PDPH $[44,45]$. Three of the four randomized controlled studies analyzed in these systemic reviews found a statistical difference in PDPH incidence. However, the study using a sham procedure to exclude the placebo effect did not show any difference. In a randomized controlled study published in 2014, Stein et al. [46] found a significant reduction in $\mathrm{PDPH}$ in 11 of 60 patients who received a prophylactic epidural blood patch compared to the 39 of 49 patients who did not $(\mathrm{P}<$ 0.0001). This study was flawed because no sham epidural blood patch was used. Although a prophylactic epidural blood patch was effective for some studies, methodological limitations were identified in these studies such as problems with randomization, blindness, and small sample size. A prophylactic epidural blood patch should be performed after full recovery of sensation to prevent the inhibition of coagulation by local anesthetics [47] or accidental total spinal anesthesia [48]. In addition, the occurrence of pain can be a signal to stop the injection of blood. In this context, the procedure is usually performed at least $5 \mathrm{~h}$ after the last dose of epidural anesthetic. Risks associated with prophylactic epidural blood patches include common transient complications such as backache and rare complications such as a neurological deficit or infection.

\section{Intrathecal catheter placement}

The placement of an intrathecal catheter through the dural puncture hole for up to $24 \mathrm{~h}$ has been proposed as a preventive measure for PDPH. Theoretically, this intervention prevents CSF leakage by sealing the dural hole, and maintaining the catheter for up to $24 \mathrm{~h}$ results in a localized inflammatory response that encourages hole closure [49]. This procedure allows immediate analgesia during labor through the intrathecal catheter, negating the risk of repeated dural punctures [50-52]. Systematic reviews $[44,45,53]$ have indicated that intrathecal catheter placement 
does not significantly reduce the incidence of PDPH. However, this intervention does reduce the overall severity of PDPH and the need for an epidural blood patch. Similarly, in a retrospective study of 218 inadvertent dural puncture cases, Bolden and Gebre [54] compared the incidence of PDPH and the need for an epidural blood patch between a re-sited epidural group and a spinal catheter group. There were no differences in incidence between the groups (68.0 vs. $55.9 \%$, odds ratio [OR]: 1.7, 95\% CI: $1.0-2.9, \mathrm{P}=0.07)$. The need for an epidural blood patch was significantly reduced in the spinal catheter group compared to the re-sited epidural group (52.0\% to $20.3 \%$, OR: $4.2,95 \% \mathrm{CI}$ : 2.4-7.6, $\mathrm{P}<0.001)$. The addition of intrathecal saline to the intrathecal catheter reduced the need further, from $55.2 \%$ to 25.0\% (OR: 3.7, 95\% CI: 1.2-11.2, P = 0.02). Intrathecal catheterization has potential risks such as meningitis or abscess [55], arachnoiditis, and cauda equina syndrome [56,57].

\section{Epidural saline administration}

Saline injected into the epidural space may decrease CSF loss by reducing the pressure gradient between the epidural and subarachnoid spaces. Therefore, epidural saline has been used to prevent PDPH with variable success. However, a systematic review and meta-analysis of epidural saline failed to demonstrate the prophylactic effects of epidural saline on the incidence of PDPH or the need for an epidural blood patch [44]. A prophylactic epidural blood patch, intrathecal catheter placement, and epidural saline injection are not considered routine preventative therapies due to lack of substantial evidence. A careful decision regarding the use of these prophylactic interventions is needed because of this lack of evidence and the potential risks.

\section{Treatment}

\section{Conservative}

Conservative measures for the first 24 to $48 \mathrm{~h}$ are considered the initial management strategy, because more than $85 \%$ of PDPH resolves with conservative treatment [33]. These measures include bed rest, intravenous hydration, caffeine supplementation, and analgesic medication. Obviously, bed rest in the supine position may improve the symptoms of $\mathrm{PDPH}$, although there is no evidence for prevention or a faster recovery. Sometimes, the prone position relieves PDPH because the increased intra-abdominal pressure results in increased CSF pressure. Oral hydration has been a popular therapy for $\mathrm{PDPH}$, although there is no evidence that aggressive hydration is beneficial in a patient with normal fluid intake [58]. However, dehydration should be avoided to limit its aggravating effect on the severity of PDPH [33].

Online access in http://ekja.org
Since caffeine was first used as a therapeutic agent for PDPH in 1949, many investigators recommend caffeine as a therapeutic option. Caffeine increases cerebral vasoconstriction by blocking adenosine receptors and leads to augmented CSF production by stimulating sodium-potassium pumps [59]. Mathew and Wilson [60] demonstrated a reduction in cerebral blood flow after the intravenous administration of caffeine benzoate for the treatment of PDPH. Caffeine was superior to a placebo for pain relief in PDPH. However, it resulted in transient, non-sustained relief of the headache and did not reduce the need for an epidural blood patch [61-63]. Another methylxanthine, theophylline, is also a cerebral vasoconstrictor and improves the pain severity score more than the placebo acetaminophen in randomized studies $[64,65]$. Gabapentinoids are similar in structure to the endogenous neurotransmitter gamma-amino-butyric acid, but their exact mechanism for treating PDPH is unclear. Some of their activity may modulate the release of excitatory neurotransmitters via an interaction with voltage-dependent calcium channels [66]. Gabapentin effectively decreased the pain score associated with PDPH compared to placebo or ergotamine plus caffeine [67]. In a randomized study comparing oral gabapentin (300 mg), oral pregabalin (100 mg), and oral acetaminophen (500 mg) administered three times daily for three days, both gabapentin and pregabalin significantly reduced the severity of $\mathrm{PDPH}$, although pregabalin was more effective [68].

Sumatriptan is a serotonin receptor antagonist used for the treatment of migraine as a cerebral vasoconstrictor. A few case reports have described the relief of PDPH with sumatriptan $[69,70]$.

\section{Invasive}

Patients who do not respond to conservative treatment within $48 \mathrm{~h}$ require more aggressive interventions. An epidural blood patch is considered the treatment of choice for moderate and severe PDPH, with success rates of 61-98\% [71-75]. Based on the success rates, an epidural blood patch seems to be less effective for the obstetric population. Stride and Cooper [23] reported 64\% complete relief of PDPH after the first blood patch. This lower success rate may be related to the large-gauge needle puncture of the dura during epidural analgesia.

The postulated mechanism of action of the epidural blood patch involves sealing the dural puncture site. Magnetic resonance imaging studies have found that epidural blood adheres to the thecal sac, resulting in clot formation for up to 18-24 h [76]. The pain relief is often rapid after application of a blood patch, although the CSF volume is not restored immediately. Therefore, the sudden relief cannot be explained by the puncture site closure. Carrie [77] hypothesized that the epidural injection of blood increases the lumbar CSF pressure, subsequently restor- 
ing the intracranial CSF pressure and resulting in reflex cerebral vasoconstriction.

Observational studies report that an epidural blood patch within 24-48 h of dural puncture is less effective [72,78,79]. Early onset PDPH is likely to be more severe; therefore, selection bias is possible. Alternatively, if the therapeutic benefit of an epidural blood patch is due to clot formation at the dural puncture site, factors inhibiting clot formation result in unfavorable effects. First, the initial high CSF flow may displace the clot. Second, if the epidural blood patch is performed too early, clot degradation may occur and prevent hole closure [80].

Although the optimal volume of blood required for a successful epidural blood patch is not known, volumes ranging from 5 to $30 \mathrm{ml}$ have been reported [44,72]. Paech et al. [72] randomized 121 patients to receive 15,20 , or $30 \mathrm{ml}$ autologous blood during an epidural blood patch. The efficacy of the epidural blood patch was similar in all of the three groups, with a success rate of $70 \%$. However, the authors found that $19 \%$ and $46 \%$ of those randomized to the $20 \mathrm{ml}$ and $30 \mathrm{ml}$ volumes, respectively, failed to receive the assigned volume because of injection pain. Because the epidural space varies in capacity and compliance, patients experienced pain during injection before a volume of 30 $\mathrm{ml}$ was administered. Similarly, a recent retrospective review by Booth et al. [81] reported that increasing the blood volume up to $30 \mathrm{ml}$ did not reduce the need for a repeated epidural blood patch, when the final volume was primarily determined by back pain during injection.

The epidural injection of colloids is a useful alternative to blood if an epidural blood patch is contraindicated. Dextran-40 $[82,83]$ or hydroxyethyl starch [84] have been described with various success rates. Colloids are thought to result in increased epidural pressure and decreased CSF leakage. Complications include transient discomfort and a burning sensation. Although evidence is limited, colloid solutions can be suggested in patients who refuse an epidural blood patch or when an epidural blood patch is ineffective.

The greater occipital nerve, which is derived from the dorsal root of the second cervical nerve, is the main sensory nerve in the occipital region. Greater occipital nerve blocks have been used for the treatment of different types of headache. A study of greater occipital nerve block for the treatment of PDPH showed beneficial effects in reducing pain severity, although the evidence is limited. Several authors have suggested its use as an alternative to an epidural blood patch since it is less invasive and leads to prompt symptom relief $[85,86]$.

\section{Conclusions}

Since PDPH can occur after puncture of the dura matter, the most effective method for decreasing its incidence is to develop techniques that minimize dural hole formation during spinal block and that prevent inadvertent dural puncture during epidural block. With better awareness of the risk factors related with PDPH, it is important for clinicians to be vigilant when performing spinal or epidural blocks. In reality, inadvertent puncture of the dura mater still occurs and PDPH continues to be a problem in these patients. Although various prophylactic interventions after inadvertent dural puncture have been suggested based on risk factors and pathophysiologic concerns, there is still insufficient evidence of their benefits. For the treatment of PDPH, an epidural blood patch is most effective treatment modality, with a high rate of success. Several other treatment modalities for PDPH are available, but high-level evidence supporting their efficacy is still needed. Overall, further investigation including large qualified trials is warranted, and careful attention should be paid to these issues until substantial evidence is available.

\section{References}

1. Choi PT, Galinski SE, Takeuchi L, Lucas S, Tamayo C, Jadad AR. PDPH is a common complication of neuraxial blockade in parturients: a meta-analysis of obstetrical studies. Can J Anaesth 2003; 50: 460-9.

2. Collier CB. Complications of regional anesthesia. In: Textbook of Obstetric Anesthesia. Edited by Birnbach DJ, Gatt SP, Datta S: New York, Churchill Livingstone. 2000, pp 504-23.

3. Webb CA, Weyker PD, Zhang L, Stanley S, Coyle DT, Tang T, et al. Unintentional dural puncture with a Tuohy needle increases risk of chronic headache. Anesth Analg 2012; 115: 124-32.

4. Turnbull DK, Shepherd DB. Post-dural puncture headache: pathogenesis, prevention and treatment. Br J Anaesth 2003; 91: 718-29.

5. Headache Classification Subcommittee of the International Headache Society. The International Classification of Headache Disorders: 2nd edition. Cephalalgia 2004; 24 Suppl 1: 9-160.

6. Amorim JA, Gomes de Barros MV, Valença MM. Post-dural (post-lumbar) puncture headache: risk factors and clinical features. Cephalalgia 2012; 32: 916-23.

7. Douglas MJ, Ward ME, Campbell DC, Bright SB, Merrick PM. Factors involved in the incidence of post-dural puncture headache with the 25 gauge Whitacre needle for obstetric anesthesia. Int J Obstet Anesth 1997; 6: 220-3. 
8. Lybecker H, Møller JT, May O, Nielsen HK. Incidence and prediction of postdural puncture headache. A prospective study of 1021 spinal anesthesias. Anesth Analg 1990; 70: 389-94.

9. Lybecker H, Djernes M, Schmidt JF. Postdural puncture headache (PDPH): onset, duration, severity, and associated symptoms. An analysis of 75 consecutive patients with PDPH. Acta Anaesthesiol Scand 1995; 39: 605-12.

10. Goldszmidt E, Kern R, Chaput A, Macarthur A. The incidence and etiology of postpartum headaches: a prospective cohort study. Can J Anaesth 2005; 52: 971-7.

11. Hammad T, DeDent A, Algahtani R, Alastal Y, Elmer L, Medhkour A, et al. Posterior Reversible Encephalopathy Syndrome Secondary to CSF Leak and Intracranial Hypotension: A Case Report and Literature Review. Case Rep Neurol Med 2015; 2015: 538523.

12. Pugliese S, Finocchi V, Borgia ML, Nania C, Della Vella B, Pierallini A, et al. Intracranial hypotension and PRES: case report. J Headache Pain 2010; 11: 437-40.

13. Shah R, Kubisz-Pudelko A, Reid J. Posterior reversible encephalopathy syndrome following an inadvertent dural puncture during an emergency laparotomy for ischemic colitis - a case report. Local Reg Anesth 2014; 7: 1-4.

14. Gómez-Ríos MÁ, Fernández-Goti MC. Pneumocephalus after inadvertent dural puncture during epidural anesthesia. Anesthesiology 2013; 118: 444.

15. Cuypers V, Van de Velde M, Devroe S. Intracranial subdural haematoma following neuraxial anaesthesia in the obstetric population: a literature review with analysis of 56 reported cases. Int J Obstet Anesth 2016; 25: 58-65.

16. Lim G, Zorn JM, Dong YJ, DeRenzo JS, Waters JH. Subdural Hematoma Associated With Labor Epidural Analgesia: A Case Series. Reg Anesth Pain Med 2016; 41: 628-31.

17. Bleeker CP, Hendriks IM, Booij LH. Postpartum post-dural puncture headache: is your differential diagnosis complete? Br J Anaesth 2004; 93: 461-4.

18. Morewood GH. A rational approach to the cause, prevention and treatment of postdural puncture headache. CMAJ 1993; 149: $1087-93$.

19. Grant R, Condon B, Hart I, Teasdale GM. Changes in intracranial CSF volume after lumbar puncture and their relationship to post-LP headache. J Neurol Neurosurg Psychiatry 1991; 54: 440-2.

20. Di Cianni S, Rossi M, Casati A, Cocco C, Fanelli G. Spinal anesthesia: an evergreen technique. Acta Biomed 2008; 79: 9-17.

21. Kuczkowski KM. Post-dural puncture headache in the obstetric patient: an old problem. New solutions. Minerva Anestesiol 2004; 70: 82330.

22. Liu H, Kalarickal PL, Rosinia F. A case of paradoxical presentation of postural postdural puncture headache. J Clin Anesth 2012; 24: 255-6.

23. Stride PC, Cooper GM. Dural taps revisited. A 20-year survey from Birmingham Maternity Hospital. Anaesthesia 1993; 48: 247-55.

24. Angle P, Thompson D, Halpern S, Wilson DB. Second stage pushing correlates with headache after unintentional dural puncture in parturients. Can J Anaesth 1999; 46: 861-6.

25. Jabbari A, Alijanpour E, Mir M, Bani Hashem N, Rabiea SM, Rupani MA. Post spinal puncture headache, an old problem and new concepts: review of articles about predisposing factors. Caspian J Intern Med 2013; 4: 595-602.

26. Kuntz KM, Kokmen E, Stevens JC, Miller P, Offord KP, Ho MM. Post-lumbar puncture headaches: experience in 501 consecutive procedures. Neurology 1992; 42: 1884-7.

27. Faure E, Moreno R, Thisted R. Incidence of postdural puncture headache in morbidly obese parturients. Reg Anesth 1994; 19: 361-3.

28. Miu M, Paech MJ, Nathan E. The relationship between body mass index and post-dural puncture headache in obstetric patients. Int J Obstet Anesth 2014; 23: 371-5.

29. Peralta F, Higgins N, Lange E, Wong CA, McCarthy RJ. The relationship of body mass index with the incidence of postdural puncture headache in parturients. Anesth Analg 2015; 121: 451-6.

30. Dodge HS, Ekhator NN, Jefferson-Wilson L, Fischer M, Jansen I, Horn PS, et al. Cigarette smokers have reduced risk for post-dural puncture headache. Pain Physician 2013; 16: E25-30.

31. Schmittner MD, Terboven T, Dluzak M, Janke A, Limmer ME, Weiss C, et al. High incidence of post-dural puncture headache in patients with spinal saddle block induced with Quincke needles for anorectal surgery: a randomised clinical trial. Int J Colorectal Dis 2010; 25: 77581.

32. Gisore E, Mung'ayi V, Sharif T. Incidence of post dural puncture headache following caesarean section under spinal anaesthesia at the Aga Khan University Hospital, Nairobi. East Afr Med J 2010; 87: 227-30.

33. Ahmed SV, Jayawarna C, Jude E. Post lumbar puncture headache: diagnosis and management. Postgrad Med J 2006; 82: 713-6.

34. Flaatten H, Rodt SA, Vamnes J, Rosland J, Wisborg T, Koller ME. Postdural puncture headache. A comparison between 26- and 29-gauge needles in young patients. Anaesthesia 1989; 44: 147-9.

35. Kuczkowski KM, Eisenmann UB. Hypertensive encephalopathy mimicking postdural puncture headache in a parturient beyond the edge of reproductive age. Anesth Analg 2004; 99: 1873-4.

36. Richman JM, Joe EM, Cohen SR, Rowlingson AJ, Michaels RK, Jeffries MA, et al. Bevel direction and postdural puncture headache: a metaanalysis. Neurologist 2006; 12: 224-8.

37. Norris MC, Leighton BL, DeSimone CA. Needle bevel direction and headache after inadvertent dural puncture. Anesthesiology 1989; 70: 729-31.

38. Oedit R, van Kooten F, Bakker SL, Dippel DW. Efficacy of the epidural blood patch for the treatment of post lumbar puncture headache 
BLOPP: a randomised, observer-blind, controlled clinical trial [ISRCTN 71598245]. BMC Neurol 2005; 5: 12.

39. Baysinger CL, Pope JE, Lockhart EM, Mercaldo ND. The management of accidental dural puncture and postdural puncture headache: a North American survey. J Clin Anesth 2011; 23: 349-60.

40. Arevalo-Rodriguez I, Ciapponi A, Roqué i Figuls M, Muñoz L, Bonfill Cosp X. Posture and fluids for preventing post-dural puncture headache. Cochrane Database Syst Rev 2016; 3: CD009199.

41. Halker RB, Demaerschalk BM, Wellik KE, Wingerchuk DM, Rubin DI, Crum BA, et al. Caffeine for the prevention and treatment of postdural puncture headache: debunking the myth. Neurologist 2007; 13: 323-7.

42. Al-metwalli RR. Epidural morphine injections for prevention of post dural puncture headache. Anaesthesia 2008; 63: 847-50.

43. Hakim SM. Cosyntropin for prophylaxis against postdural puncture headache after accidental dural puncture. Anesthesiology 2010; 113: 413-20.

44. Apfel CC, Saxena A, Cakmakkaya OS, Gaiser R, George E, Radke O. Prevention of postdural puncture headache after accidental dural puncture: a quantitative systematic review. Br J Anaesth 2010; 105: 255-63.

45. Bradbury CL, Singh SI, Badder SR, Wakely LJ, Jones PM. Prevention of post-dural puncture headache in parturients: a systematic review and meta-analysis. Acta Anaesthesiol Scand 2013; 57: 417-30.

46. Stein MH, Cohen S, Mohiuddin MA, Dombrovskiy V, Lowenwirt I. Prophylactic vs therapeutic blood patch for obstetric patients with accidental dural puncture--a randomised controlled trial. Anaesthesia 2014; 69: 320-6.

47. Tobias MD, Pilla MA, Rogers C, Jobes DR. Lidocaine inhibits blood coagulation: implications for epidural blood patch. Anesth Analg 1996; 82: 766-9.

48. Leivers D. Total spinal anesthesia following early prophylactic epidural blood patch. Anesthesiology 1990; 73: 1287-9.

49. Strupp M, Brandt T, Müller A. Incidence of post-lumbar puncture syndrome reduced by reinserting the stylet: a randomized prospective study of 600 patients. J Neurol 1998; 245: 589-92.

50. Russell IF. A prospective controlled study of continuous spinal analgesia versus repeat epidural analgesia after accidental dural puncture in labour. Int J Obstet Anesth 2012; 21: 7-16.

51. Gaiser R. Postdural puncture headache. Curr Opin Anaesthesiol 2006; 19: 249-53.

52. Bezov D, Ashina S, Lipton R. Post-dural puncture headache: Part II--prevention, management, and prognosis. Headache 2010; 50: 1482-98.

53. Heesen M, Klöhr S, Rossaint R, Walters M, Straube S, van de Velde M. Insertion of an intrathecal catheter following accidental dural puncture: a meta-analysis. Int J Obstet Anesth 2013; 22: 26-30.

54. Bolden N, Gebre E. Accidental dural puncture management: 10-year experience at an academic tertiary care center. Reg Anesth Pain Med 2016; 41: 169-74.

55. Bevacqua BK, Slucky AV, Cleary WF. Is postoperative intrathecal catheter use associated with central nervous system infection? Anesthesiology 1994; 80: 1234-40.

56. Moore JM. Continuous spinal anesthesia. Am J Ther 2009; 16: 289-94.

57. Rigler ML, Drasner K, Krejcie TC, Yelich SJ, Scholnick FT, DeFontes J, et al. Cauda equina syndrome after continuous spinal anesthesia. Anesth Analg 1991; 72: 275-81.

58. Berger CW, Crosby ET, Grodecki W. North American survey of the management of dural puncture occurring during labour epidural analgesia. Can J Anaesth 1998; 45: 110-4.

59. Straube A, Neudert C, Glas M, Brüning R, Padovan CS. The so-called spontaneous low CSF pressure pressure syndrome. Case results indicating a disturbance in CSF/blood volume regulation. Nervenarzt 2004; 75: 1194-9.

60. Mathew RJ, Wilson WH. Caffeine induced changes in cerebral circulation. Stroke 1985; 16: 814-7.

61. Camann WR, Murray RS, Mushlin PS, Lambert DH. Effects of oral caffeine on postdural puncture headache. A double-blind, placebocontrolled trial. Anesth Analg 1990; 70: 181-4.

62. Yücel A, Ozyalçin S, Talu GK, Yücel EC, Erdine S. Intravenous administration of caffeine sodium benzoate for postdural puncture headache. Reg Anesth Pain Med 1999; 24: 51-4.

63. Basurto Ona X, Osorio D, Bonfill Cosp X. Drug therapy for treating post-dural puncture headache. Cochrane Database Syst Rev 2015; (7): CD007887.

64. Mahoori A, Hassani E, Noroozinia H, Javaheri N, Hatami S. Theophylline versus acetaminophen in the treatment of post-dural puncture headache (PDPH). Middle East J Anaesthesiol 2013; 22: 289-92.

65. Ergün U, Say B, Ozer G, Tunc T, Sen M, Tüfekcioglu S, et al. Intravenous theophylline decreases post-dural puncture headaches. J Clin Neurosci 2008; 15: 1102-4.

66. Beal B, Moeller-Bertram T, Schilling JM, Wallace MS. Gabapentin for once-daily treatment of post-herpetic neuralgia: a review. Clin Interv Aging 2012; 7: 249-55.

67. Erol DD. The analgesic and antiemetic efficacy of gabapentin or ergotamine/caffeine for the treatment of postdural puncture headache. Adv Med Sci 2011; 56: 25-9.

68. Mahoori A, Noroozinia H, Hasani E, Saghaleini H. Comparing the effect of pregabalin, gabapentin, and acetaminophen on post-dural puncture headache. Saudi J Anaesth 2014; 8: 374-7.

69. Carp H, Singh PJ, Vadhera R, Jayaram A. Effects of the serotonin-receptor agonist sumatriptan on postdural puncture headache: report of 
six cases. Anesth Analg 1994; 79: 180-2.

70. Connelly NR, Parker RK, Rahimi A, Gibson CS. Sumatriptan in patients with postdural puncture headache. Headache 2000; 40: 316-9.

71. Bucklin BA, Hawkins JL, Anderson JR, Ullrich FA. Obstetric anesthesia workforce survey: twenty-year update. Anesthesiology 2005; 103: 645-53.

72. Paech MJ, Doherty DA, Christmas T, Wong CA. The volume of blood for epidural blood patch in obstetrics: a randomized, blinded clinical trial. Anesth Analg 2011; 113: 126-33.

73. Martin JA, Hamilton BE, Osterman MJ, Curtin SC, Matthews TJ. Births: final data for 2013. Natl Vital Stat Rep 2015; 64: 1-65.

74. Taivainen T, Pitkänen M, Tuominen M, Rosenberg PH. Efficacy of epidural blood patch for postdural puncture headache. Acta Anaesthesiol Scand 1993; 37: 702-5.

75. van Kooten F, Oedit R, Bakker SL, Dippel DW. Epidural blood patch in post dural puncture headache: a randomised, observer-blind, controlled clinical trial. J Neurol Neurosurg Psychiatry 2008; 79: 553-8.

76. Beards SC, Jackson A, Griffiths AG, Horsman EL. Magnetic resonance imaging of extradural blood patches: appearances from $30 \mathrm{~min}$ to $18 \mathrm{~h}$. Br J Anaesth 1993; 71: 182-8.

77. Carrie LE. Epidural blood patch: why the rapid response? Anesth Analg 1991; 72: 129-30.

78. Bezov D, Lipton RB, Ashina S. Post-dural puncture headache: part I diagnosis, epidemiology, etiology, and pathophysiology. Headache 2010; 50: 1144-52.

79. Safa-Tisseront V, Thormann F, Malassiné P, Henry M, Riou B, Coriat P, et al. Effectiveness of epidural blood patch in the management of post-dural puncture headache. Anesthesiology 2001; 95: 334-9.

80. Sachs A, Smiley R. Post-dural puncture headache: the worst common complication in obstetric anesthesia. Semin Perinatol 2014; 38: 38694.

81. Booth JL, Pan PH, Thomas JA, Harris LC, D'Angelo R. A retrospective review of an epidural blood patch database: the incidence of epidural blood patch associated with obstetric neuraxial anesthetic techniques and the effect of blood volume on efficacy. Int J Obstet Anesth 2016 [Epub ahead of print].

82. Reynvoet ME, Cosaert PA, Desmet MF, Plasschaert SM. Epidural dextran 40 patch for postdural puncture headache. Anaesthesia 1997; 52: 886-8.

83. Bel I, Moreno LA, Gomar C. Epidural dextran-40 and paramethasone injection for treatment of spontaneous intracranial hypotension. Can J Anaesth 2006; 53: 591-4.

84. Sun S, Huang SQ. Epidural injection of hydroxyethyl starch in the management of post-dural puncture headache: a case series. Int J Clin Exp Med 2015; 8: 8254-8.

85. Niraj G, Kelkar A, Girotra V. Greater occipital nerve block for postdural puncture headache (PDPH): a prospective audit of a modified guideline for the management of PDPH and review of the literature. J Clin Anesth 2014; 26: 539-44.

86. Uyar Türkyilmaz E, Camgöz Eryilmaz N, Aydin Güzey N, Moraloğlu Ö. Bilateral greater occipital nerve block for treatment of post-dural puncture headache after caesarean operations. Braz J Anesthesiol 2016; 66: 445-50. 